\title{
AN INVISIBLE POPULATION - THE EXPERIENCES OF YOUNG ADULT CARERS STUDYING AT THE EASTERN INSTITUTE OF TECHNOLOGY
}

\author{
Charlotte Chisnell, Mandy Pentecost and Sue Hanna
}

\section{INTRODUCTION}

Jo arrives late to class again. She immediately looks at her phone. She doesn't have her textbook and looks really tired. You agree to give Mai another extension on an assignment because of family issues. This is a pattern with this student; you tell her that this has to stop happening.

Such scenarios are familiar to tertiary educators and are often attributed to the student's lack of self-management skills or not making study a priority. However, maybe these students have a hidden burden of responsibility and care. Could they be a young carer?

Our research explores the issues that young adult carers, aged between 18 and 25, faced while undertaking tertiary study at the Eastern Institute of Technology (EIT) while at the same time trying to balance their caring responsibilities with education. Research of this nature, involving connections and collaboration between tertiary applied researchers and professionals in the field, is essential to enhance the learning experience for young adult carers.

\section{WHAT IS A YOUNG CARER?}

Young carers and young adult carers are young people "who provide regular and ongoing care and emotional support to a family member who is physically or mentally disabled, or misuses substances [emphasis in original]" (Research in Practice, 2016, p. 2). These responsibilities are beyond what would be expected of their peers. Joseph et al. (2019) suggest that young carers in different countries share similar experiences, all of which can have an impact on their education and wellbeing.

There are an estimated 40,000 young carers in Aotearoa New Zealand (Ministry of Social Development [MSD], 2019 , p. 5), with approximately 9 percent of carers aged between 15 and 24 years (MSD, 2019, p. 9). Research indicates that the unique needs of young carers and young adult carers has not been recognised in Aotearoa New Zealand until recently. In May 202I, a Sunday television programme (Sutherland, 2021) and a subsequent Breakfast news story (Fisher, 202I) highlighted the hidden issues of young carers and young adult carers in Aotearoa New Zealand. 
During the Sunday interview Dr Saul Becker, who is an international researcher, stated:

It makes me angry, but also really sad, actually, that a country like New Zealand, which leads in the world on so many things, a civilised nation which has such fantastic values and support systems in place for so many things, has been so slow to identify young carers in your midst.

We need, particularly for New Zealand to wake up. To wake up and say, this isn't acceptable in a civilised, decent society, we have to do something to recognise and support young carers. (Sutherland, 2021)

As these groups of young people are not widely known or understood in Aotearoa New Zealand, their needs are rarely recognised. They are often an isolated demographic, who need more support to manage their additional caring responsibilities while attending school or tertiary study. In the U.K., young adult carers are four times more likely to drop out of college or university than other students (Sempik \& Becker, 20I4).

In many, if not most, families the contribution of children to day-to-day household operations is expected and encouraged. The young carer group has responsibilities which are either too demanding for their developmental stage, or take away their opportunities to 'act their age.' Dearden \& Becker (2004) assigned these responsibilities to six categories: household and gardening tasks; providing emotional support; carrying out personal care (includes bathing, feeding, lifting, administering medication); supervision of younger siblings; managing finances; and acting as translator for those with little or no English as a second language. The expectations are such that they have a detrimental effect on the young person's wellbeing and ability to fully participate in typical social activities for their age, and may limit their educational achievement. Because these tasks are, for many, just part of the necessary, every day running of the household, young caring is often invisible - even to the young carers themselves (Aldridge, 2018).

All families establish patterns of care and responsibility. In Aotearoa New Zealand, expectations within Māori and Pacific families in particular significantly shape the caring roles expected of family members. According to Drewery and Claiborne (2014, p. 5I), "responsibility and family values include contributing to the family's livelihood in a range of ways - even, sometimes, if it is seen by others, such as the child's teacher, as detrimental to their schooling." The roles taken by young carers typically develop either incrementally over time or arrive all at once as a result of a family crisis or emergency (Chikhradze et. al., 2017). Donnan's (2018) New Zealand research identified that the young person may have sole responsibility for caregiving tasks or be supporting "a burnt-out adult carer," but with a "significant helping out role" (Fisher, 202I). In Britain, The Children's Society (2013) found that young carers are more likely to come from ethnic minorities and not to have English as their first language. Addiction, family violence and mental health issues are present in approximately a third of British young carers' families (The Children's Society, 2016; Cunningham et al., 2017; Kennan et al., 2012; Research in Practice, 2016). U.K. research further points to poverty and low incomes, and being in a sole-parent family, as contributing factors (Aldridge, 2018).

Typically, these carers do not want to stop their caring responsibilities (Fisher, 202I). However, according to the research literature it is clear that their role is stressful, and that the resulting detrimental effects impact on their present and future possibilities (Children's Society, 2013, 2016; Cree, 2003; Dearden \& Becker, 2004; Moore et al., 2009). U.K. studies have identified that, for this group, educational attainment in the compulsory schooling sector falls significantly below that of other young people, with 27 percent missing school or experiencing educational difficulties, such that they are less likely to enter, or remain, in tertiary education (Children's Society, 2013, 2016; Dearden \& Becker, 2004). The incidence of mental ill-health in this group was 38 percent (Children's Society, 20 I3).

As with any situations of adversity, there is also the possibility of positive effects. Cunningham et al. (2017) identified the development of resilience as an effect for young carers. This was especially the case for those who experienced less stress, often because they felt well enough supported to be able to manage their situation, and had developed good coping strategies. For example, those who felt well-informed about their parent's illness were found to have a stronger capacity for resilience (McGibbon et al., 2018). 


\section{METHODOLOGY}

The objectives of the research were to explore the particular obstacles that young adult carers face in accessing tertiary study, and the support they require once enrolled in higher education to ensure they are able to reach their academic potential. Qualitative research is particularly useful in exploring situations and phenomena about which little is known, and where the person-centred, holistic and contextual emphasis facilitated by this methodology make it suitable to manage sensitive and emotionally charged data (Padgett, 2008). A qualitative framework also allows for an epistemological foundation informed by social constructivism, enabling a focus on the voices of the participants and how they construct their experiences within their families and within the broader narratives and expectations about tertiary study and the student experience within which they are located.

We were interested to find out:

- What/who motivates young carers to enrol in tertiary study, and how do they prepare for this experience?

- What obstacles to academic study and participation do young carers encounter in a tertiary environment?

- What coping strategies do young carers utilise to manage the demands of study and family responsibilities?

We invited participation from students who were currently enrolled as a full- or part-time student at EIT, and who were currently or previously involved between 18 and 24 years of age in providing unpaid caring responsibilities to a family member.

Due to the lack of awareness and recognition of the role of young adult carers, we prepared a participant information sheet which included a definition of an adult young carer. After reading the definition, the participants volunteered because they identified with either being a young adult carer or a former young carer.

Snowball sampling - arranged through informed and knowledgeable contacts and invitations during classes and lectures to participate in the research - was used to secure a purposive sample. Twelve respondents participated in focus groups and an additional two, who could not attend a focus group, participated in semi-structured interviews.

Focus groups and in-depth, semi-structured, individual interviews were utilised, as this method of data collection is best suited to accommodate the potential complexity of the personal and educational experiences of young adult carers (Hardill \& McDonald, 2000). The group conversations and interviews were transcribed, with data anonymised.

The transcripts were analysed using an inductive approach to data analysis which concentrates on condensing raw data to establish links between the evaluation objectives and the study findings. The focus was on the described experiences of the participants from the perspectives of their various environments, with the aim of identifying the ways in which they all contribute towards answering the evaluation questions.

The process of thematic analysis was incorporated into the research design, which allowed the researchers to identify common themes that had emerged from the data. Thematic analysis "provides a flexible and useful research tool, which can potentially provide a rich and detailed, yet complex account of data" (Braun and Clarke, 2006, p. 3), with the aim of uncovering themes in textual data at varying levels of complexity (Padgett, 2008).

During the analysis, the focus group participants' specific words and phrases were highlighted and coded, which enabled themes and emerging patterns to be identified in order to "reflect the themes in the lives of the participants" (Sheppard, 2006, p. 242).

A preliminary thematic analysis identified a number of common themes that emerged from the data, including invisibility, inevitability, isolation and loneliness, guilt, coping strategies, resilience, determination and perseverance. 


\section{FINDINGS}

Our research identified a number of themes that highlighted the impact of being a young adult carer or former young carer studying at tertiary level education at EIT. Verbatim transcripts of the expert voices of young adult carers are presented under each theme heading, articulating their lived experience.

\section{Invisibility}

In her New Zealand research, Lauren Donnan found that she could not initially find young carers, as "they did not self-identify" at first, later acknowledging, "I think I might be a young carer." In a caring role for a family member herself, it was a title she too had "stumbled upon" (Fisher, 202I). We received similar responses as participants volunteered, and during the focus groups the invisibility of the role was evident:

F: "It's a bit of a hidden thing because you don't really understand it until someone points it out to you. When he said that to me I thought, 'Wow."'

E: "The school knew I was taking time off to look after my mother on a regular basis. To my knowledge, I don't recall there ever being any specific meetings at the school to discuss how they were going to help me cope with that or anything like that."

\section{Inevitability}

There was a sense from most of the participants that the caring responsibility naturally and inevitably fell to them.

B: "I didn't have a choice."

A: "But, you know, that's what some people do - care for others, right?"

They did not question this role, or oppose it, even though they often struggled with the extra calls on their time and emotional wellbeing.

C: "Then I would think about it and, 'Do I need to be doing this?' But, then something would happen with my sister and l'd be like, 'Okay, I have to do it."'

One of the participants expressed her obligation to her family members through her Pasifika cultural lens. She could not refuse because it was an expected role:

N: "It would basically offend my relatives. In my case, if I had kind of said, 'No, I can't do this,' it would be, like, 'Oh, I do so much for you.' You couldn't really express how I was feeling."

The concept of not providing care from within the family is foreign and does not make sense:

N: "When people don't grow up in a family that's, like, tight-knit, or a culture that is, like, you help your family members, I guess, I don't know, how can you explain it to them? They wouldn't understand. I felt like I needed to look after her, like it was my responsibility to look after my [family member]. She had done so much for our family."

\section{Disruption to personal lives}

Caring duties and the strong sense of responsibility had an inevitable impact on the participants' personal lives and their education. They reported being unable to join in usual activities of their peers, or not being able to relax if they did.

A: "I did notice that I was cancelling plans to stay home and I was under a lot of stress while I was studying, just because I was constantly putting them off to care for my relatives. It was a lot of pressure." 


\section{Isolation and loneliness}

Participants also spoke of isolation and loneliness. The invisibility of the role and the sense that it was inevitably theirs also led to a reluctance to ask for support.

M: "Because my Dad suffered from schizophrenia it was very isolating; you didn't really let people in because of his mental health state."

Most did not wish to tell too many others, including lecturers, about their circumstances:

N: "If I could, I wouldn't have told the lecturers, but I had to, because I had to tell them the reason why I was leaving, why I couldn't have come in."

One participant explained why she did not ask for help:

C: "I think before I was, like, 'No, it's not okay, you have to do everything on your own."'

\section{Tiredness}

All the participants agreed that tiredness, even "exhaustion," was a constant in their lives.

$N$ : "It's a miracle when I think back now, because I think the most time that I ever got for self-care back then was for sleep, and that was barely any sleep."

C: "Yeah, the minute that I would have to wake up it would all start again. I was just barely making it through the day."

Adding the pressure of course and assignment work to an already full schedule often meant making a choice between doing that work or getting some sleep or relaxation.

T: "The time I did have I didn't want to do schoolwork because I was exhausted."

\section{Guilt}

A number of the participants expressed guilt at not being more fully available to those they cared for, and taking time for their own pursuits such as study.

F: "I feel terrible when I can't be there for him when he rings me and asks where I am."

Participants also felt guilt at not being able to give their study the attention it required.

L: "It kind of made me upset a little bit because I would hear at that time some classmates would be, like, I'm halfway through my assignment,' and it's not due till two weeks. I'm sitting there feeling all this guilt. I just feel upset about myself, not being able to do that."

\section{Disruption to education}

Several of the participants reported that they had experienced disruption to either their schooling or tertiary education. They reported patterns of absence and distraction, not having time for assignments or extra-curricular activities.

A: "It was to the point I would be in a class and l'd get a phone call or a message, and I would just instantly freak out and be, like, 'Oh my god, what's going on? Do I have to come home? What's happening?' It was a lot."

M: "There were times where I wasn't sure if I was going to be able to do my assessments in time. I was constantly freaking out and having panic attacks and things like that." 


\section{Coping strategies}

But they survived. We were interested in how they took care of themselves and what coping strategies they adopted. Participants reported that they had few self-care strategies.

L: "There wasn't really a huge amount of coping strategy."

F: "I probably didn't look after myself as well as I should have, but I just felt there were things more pressing; there were things that needed my attention more than myself at the current time."

However, they were under constant pressure and developed a number of potentially destructive ways of dealing with the pressure. These usually involved getting "out of it."

L: "Yeah, it was basically just escaping, even for a little bit."

B: "I'd just drink the whole weekend away, and then go home. I was not in a good place. I think my worst was I developed a substance dependency and it was very bad. It was very bad."

\section{Determination and perseverance}

Despite the enormous challenges, all the participants were in tertiary education, even if their progression from schooling had been delayed. They managed their education by means that probably challenged their teachers, but they were keeping their heads just above water. For some, the situation that led to their carer role was also the driver for their educational and career goals.

B: "I guess that was the motivation there. I really wanted a degree. I wanted to do something with my life, I guess. The biggest motivator to enrol in social work was my parents."

If resilience is the ability to keep going when times are tough, for these students their ability to keep going whatever was happening was what got them through:

C: "It was, like, 'You've been through worse, you can push this off just a little bit more."'

\section{What helps?}

The participants identified a number of strategies that educational institutions have provided, or could provide, to support their learning journeys.

They valued flexibility - for example, they made optimal use of extensions for assignment submission. They also suggested providing recordings of essential information for those not in class.

L: "We could just turn on the laptop at the same time of the lecture, like a live lecture. That way we're viewing it from home, and then we're not missing out on anything, as well as the class discussions. We may not be able to give any feedback, but that way we are listening in to other people's perspectives as well."

They also thought that their institutions needed to inquire more about their situation, as life improved for them once their lecturers "knew."

C: "Most of the time they would just listen; they would just kind of be present with me while l'd be having a breakdown. It would be, like, 'What's going on?' and it's like, 'Oh, there's so much going on. We don't have food at home. The power just got turned off and I can't do anything about it. The assessment is due tomorrow and I haven't even started it yet.' So, they'd be, like, 'Okay, just relax."' 


\section{DISCUSSION AND RECOMMENDATIONS}

Young carers and young adult carers are often invisible, and can experience disruption to their personal lives, development and education. There is a growing body of evidence which recognises that whānau/informal caring can come with a hidden burden, as it did for these participants.

A different focus is needed in terms of how society supports and works with young carers and young adult carers, to encourage the further development of motivation, perseverance and resilience in young adult carers (Aldridge, 2018). Internationally, young carer policies have appeared over the past decade, with Aotearoa New Zealand entering policy development in the last two years.

In the U.K., the enactment of the Children and Families Act 2014 and the Care Act 2014 placed a duty on social services to assess needs and provide support for young carers. Although progress has been slow, finally the profile and needs of young carers have been recognised in statutes (Cheesbrough et al., 2017).

A broad definition of caring must inevitably be at the heart of policy if it is to help address the complex web of the different needs of families to reduce the burden of care, support young people who care, and address the problems that arise from caring. (Joseph et al., 2019, p. 12)

The objective of this research has been to document and collate the experiences of tertiary students at EIT, learners who identified as being either adult young carers or former young carers, and to identify areas for future development in how the institution operates which could help to support and enhance their learning experience. Young adult carers are four times more likely to drop out of higher education than their peers, or not to participate at all. (Kettell, 2020; Hill et al., 20II).

It is all too easy to label students as lacking motivation and time management, poor attendees, easily distracted, always on their phone. International evidence and our own findings suggest the need for a paradigm shift which allows tertiary institutions to identify and address some of the barriers which can impact on effective engagement and student success. Firstly, as educators we have a responsibility to understand both the role and the demands that can be associated with "invisible caring" (Hanna \& Chisnell, 2019).

The difficulty is, because the problem is invisible, we need to ask more questions. Typically, this group does not volunteer the information that they may need extra support. Often, tutors find out about their student's situation only when the student is overwhelmed. U.K. institutions are now required to include a section in their admissions forms which asks an applicant to identify their caring responsibilities (Sempik \& Becker, 2014). However, despite this change in policy, many young adult carers do not identify themselves with this demographic, a situation which highlights the need for tertiary institutions to develop clear information and policies about the unique challenges that young adult carers can face (Kettell, 2020).

Sempik and Becker (2014) and Kettell (2020) both suggest that pastoral care is crucial to support young adult carers. This view was supported by our participants, who agreed that a regular, informal 'catch up' would be welcomed to allow them to check in about their caring responsibilities and general wellbeing. The participants also suggested various mechanisms for support, such as recording classes for those not in attendance; providing support groups for students who need a space to talk; and including specific check-ins about home responsibilities as part of pastoral care. Once we know about a student's additional responsibilities, we need to identify ways to actively support them as they navigate tertiary study. Our participants were extremely grateful for assignment extensions, although it was recognised that they are not handed out easily in all programmes.

Tertiary institutions can use their online platform to support young adult carers, including recording teaching sessions and using flexible submission dates (Kettell, 2020). This approach was confirmed by our participants who suggested that additional support such as recorded teaching sessions and the provision of support groups would 
be beneficial. As educators, we should find other ways to be flexible. For example, the Bachelor of Social Work programme at EIT has two mandatory 60-day, full-time placements, which require careful advance planning for all students with family responsibilities. Such requirements can seem quite inflexible, and staff should be encouraged to work with students and placement agencies to make alternative arrangements when the ability to attend has become an issue.

Perhaps one of the biggest challenges will be simply raising awareness of the issues that many adult young carers can face and providing consistent, unified support across institutions. "Ensuring staff are aware of what support services are available, and understand[ing] how to signpost students effectively, may help alleviate the feeling of being 'passed on' experienced by some [young adult carers]" (Kettle, 2020, p. 109).

Ultimately, we should endeavour to understand the distinctive challenges and barriers that young adult carers face, including the responsibility to encourage this group to recognise their unique status.

Charlotte Chisnell was a social worker in the U.K., working in the practice area of child protection and youth justice. She is currently the programme co-ordinator on the Bachelor of Social Work at Eastern Institute of Technology. Her research interests include safeguarding children and raising awareness of child sexual exploitation and the issues around young carers.

(D) https://orcid.org/0000-0002-9034-2965

Mandy Pentecost is a counsellor with a long history of involvement in adult and tertiary education. She is assistant head of the School of Education and Social Sciences at the Eastern Institute of Technology.

(D) https://orcid.org/0000-0002-7038-981।

Sue Hanna is the academic portfolio lead for social work at Greenwich University, London. Sue has worked in social work education for many years and previously worked in health and hospital-based social work services and child protection. Sue's research interests involve the effective engagement and support of vulnerable populations.

(D) https://orcid.org/0000-0002-0198-3358

\section{REFERENCES}

Aldridge, J. (2018). Where are we now? Twenty-five years of research, policy and practice on young carers. Critical Social Policy, 38(I), 155-165. https://doi.org//0/1177/0261018317724525

Aldridge, J., \& Becker, S. (1993). Punishing children for caring: The hidden cost of young carers. Children \& Society, 7(4), 376-387. https://doi.org//0.1111/j.1099-0860.1993.tb00293.x

Banks, P., Cogan, N., Riddell, S., Deeley, S., Hill, M., \& Tisdall, K. (2002). Does the covert nature of caring prohibit the development of effective services for young carers? British Journal of Guidance and Counselling, 30(3), 229-246. https://doi. org/10.1080/030698802100002281

Bee, P., Berzins, K., Calam, R., Pryjmachuk, S., \& Abel, K. M. (2013). Defining quality of life in the children of parents with severe mental illness: A preliminary stakeholder-led model. PloS One, 8(9), Article e73739. https://doi.org/I0.137//journal. pone.0073739

Braun, V. and Clarke, V. (2006) Using thematic analysis in psychology. Qualitative Research in Psychology, 3(2), 77-101.

Bulman, M. (2018, January 28). Number of young carers in the UK soars by 10,000 in four years, figures show. Independent. https://www.independent.co.uk/news/uk/home-news/young-carers-uk-numbersrise-figures-support-family-social-carebenefitscommunity-a8177806.html

Charles, G., Stainton, T., \& Marshall, S. (2009). Young carers: Mature before their time. Reclaiming Children \& Youth, 18(2), 39-41. 
Cheesbrough, S., Harding, C., Webster, H., \& Taylor, L. (with Aldridge, J.). (2017). The lives of young carers in England: Omnibus survey report, January 2017. https://assets.publishing.service.gov.uk/government/uploads/system/uploads/attachment_ data/file/582575/Lives_of_young_carers_in_England_Omnibus_research_report.pdf

Chikhradze, N., Knecht, C., \& Metzing, S. Young carers: Growing up with chronic illness in the family - A systematic review 20072017. Journal of Compassionate Health Care, 4(I), Article 12. https://doi.org/10.1186/s40639-017-004I-3

Children's Society. (2013). Hidden from view.

Children's Society. (2016). Supporting young carers and their families.

Cree, V. E. (2003). Worries and problems of young carers: Issues for mental health. Child \& Family Social Work, 8(4), 30 I-309. https://doi.org/I0.1046/j.1365-2206.2003.00292.

Cunningham, L., Shochet, I., Smith, C., \& Wurfl, A. (2017). A qualitative evaluation of an innovative resilience-building camp for young carers. Child \& Family Social Work, 22(2), 700-710.

Davies, C., \& Ward, H. (201I). Safeguarding children across services: Messages from research. Jessica Kingsley Publishers.

Dearden, C., \& Becker, S. (2004). Young carers in the UK: 2004 report. Department for Education.

Drewery, W., \& Claiborne, L. B. (2014). Human development. McGraw Hill Education.

Fisher, M. (Executive Producer). (2021, May 10). Breakfast. [Television broadcast]. https://www.tvnz.co.nz/one-news/newzealand/nz-should-embarrassed-its-global-ranking-young-carers-says-world-leading-expert

Hanna, S., \& Chisnell, C. (2019). An invisible population - Young carers in Aotearoa New Zealand. Aotearoa New Zealand Social Work, 3I(2), 7-17. https://doi.org/l0.1II57/anzswj-vol3liss2id636

Hill, T., Thomson, C., \& Cass, B. (201I). Young carers: Location, education and employment disadvantage. Australian Journal of Labour Economics, 14(2), 173-198.

Joseph, S., Kendall, C., Toher, D., Sempik, J., Holland, J., \& Becker, S. (2019). Young carers in England: Findings from the 2018 BBC survey on the prevalence and nature of caring among young people. Child: Care, Health and Development, 45(4), 606-612.

Joseph, S., Sempik, J., Leu, A., \& Becker, S. (2020). Young carers research, practice and policy: An overview and critical perspective on possible future directions. Adolescent Research Review, 5, 77-89. https://doi.org/10.1007/s40894-019-00119-9

Kennan, D., Fives, A., \& Canavan, J. (2012). Accessing a hard to reach population: Reflections on research with young carers in Ireland. Child and Family Social Work, 17, 275-282. https://doi:org//I0.1 I II/j.1365-2206.2011.00778.x

Kettell, L. (2020). Young adult carers in higher education: The motivations, barriers and challenges involved - A UK study. Journal of Further and Higher Education, 44(I), I00-1 I2. https://doi.org/I0.1080/0309877X.2018.1515427

Manning, V., Best, D. W., Faulkner, N., \& Titherington, E. (2009). New estimates of the number of children living with substance misusing parents: Results from UK national household surveys. BMC Public Health, 9(377), 1-12. https://doi. org/I0/II86/147I-2458-9-377

McDonald, J., Cumming, J., \& Dew, K. (2009). An exploratory study of young carers and their families in NZ. Kotuitui: Journal of Social Service Online, 4(2), II5-129. https://doi.org//0.1080/1177083X.2009.9522448

McGibbon, M., Spratt, T., \& Davidson, G. (2018). Young carers in Northern Ireland: Perceptions of and responses to illness and disability within the family. British Journal of Social Work, 49(5), II62-1179. https://doi.org/l0.1093/bjsw/bcyl02

Ministry of Social Development. (2014). The New Zealand carers' strategy action plan.

Ministry of Social Development. (2019). Mahi Aroha - Caring for carers: The discussion document on the proposed carers' strategy action plan 2019-2023.

Moore, T., McArthur, M., \& Morrow, R. (2009). Attendance, achievement and participation: Young carers' experiences of school in Australia. Australian Journal of Education, 53(I), 5-18.

Munro, E. (20II). The Munro review of child protection: Final report: A child-centred system. Department for Education.

Newman, T., \& Blackburn, S. (2002). Transitions in the lives of children and young people: Resilience factors. Scottish Executive Department of Education.

Phelps, D. (2017). The voices of young carers in policy and practice. Social Inclusion, 5(3), II3-121. https://doi.org/l0.17645/ si.v5i3.965

Research in Practice. (2016). Young carers and their families: Confident assessment practice.

Sempik, J., \& Becker, S. (2014). Young adult carers at college and university. Carers Trust.

Sheppard, M. (2006). Social exclusion and social work: The idea of practice. Ashgate.

Sutherland, N. (2021, May 9). NZ should be 'embarrassed' about its global ranking on young carers, says a world leading expert. One News. https://www.tvnz.co.nz/one-news/new-zealand/nz-should-embarrassed-its-global-ranking-young-carers-saysworld-leading-expert 